Saudi Journal of Biomedical Research

Abbreviated Key Title: Saudi J Biomed Res ISSN 2518-3214 (Print) |ISSN 2518-3222 (Online)

\title{
Isolation of the Pathogenic Bacteria from Banknotes and Coins in Khartoum City Pre-COVID-19 Era, Sudan
}

\author{
Abdelhakam H. Ali ${ }^{1}$, Algawhara Tagalsir Abdalrahman ${ }^{1}$, Ashwag Mohammed Ahmed ${ }^{1}$, Duaa Haj Ali Hajhamed ${ }^{1}$, Maali \\ Bilal Ahmed Abdalrazig ${ }^{1}$, Mawada Hassan Fadllalah Mohammed ${ }^{1}$, Mosab Nouraldein Mohammed Hamad ${ }^{3 *}$, Mogadam \\ Bahar $^{1}$ \\ ${ }^{1}$ Faculty of Medical Laboratory Sciences, University of Al Butana, Sudan \\ ${ }^{2}$ Department of Medical Microbiology, Faculty of Medical Laboratory Sciences, National Ribat University, Sudan \\ ${ }^{3}$ Phylum of Medical Parasitology, Medical Laboratory Sciences Department, Faculty of Health Science, Elsheikh Abdallah Elbadri University, Berber, \\ Sudan
}

DOI: $10.36348 /$ sjbr.2020.v05i12.004 $\quad$ | Received: 02.12.2020 | Accepted: 16.12.2020 | Published: 20.12 .2020

*Corresponding author: Mosab Nouraldein Mohammed Hamad

\section{Abstract}

Background: Coinage notes and moneys are widely exchanged between various communities for trade, which may serve as a carrier of microbes and lead to transmission of infectious diseases. The aim of this study is to isolate microbial contamination of Sudan currency notes and coins that life threatening condition of Sudanese people. Methods: One hundred samples (48 currency notes and 52 coins) were collected from various place of society namely, bus conductor, cafeteria, vegetable seller and pharmacies to reveal the bacteria profile of circulating coins and currency notes. Results: Out of the total number of all isolates from all the coins and currency put together was 169, of which the pathogenic isolate count 62(36\%) organism Staphylococcus aureus 28(17\%), Klebsiella pneumonia 14(8\%), Enterobacter species 9(5\%), Enterococcus faecalis 6(4\%), Pseudomonas aeruginosa 3(2\%), Escherichia coli 2(1\%). While the remnant which consider as Normal flora was form 107 (64\%) organism Bacillus species 33 (20\%), Staphylococcus epidermidis 24(14\%), Micrococcus Species 1(1\%) and fungi was present 49(29\%) of all isolates. The result of sensitivity test toward the pathogenic isolates showed that overall isolates Exhibited high resistance to vancomycin and Penicillin, while absent or little resistance was against antibiotics like, gentamicin, ciprofloxacin, and tetracycline. Conclusion: The study suggested that Sudanese paper currency and coins are highly contaminated with pathogenic microorganisms and this contamination may play a significant role in transmission of infectious diseases. Hence, great care must be taken while handling money during the preparation and handling of food to avoid cross contamination.

Keywords: Banknotes, Coins, Sudanese currency.

Copyright ( $) 2020$ The Author(s): This is an open-access article distributed under the terms of the Creative Commons Attribution 4.0 International License (CC BY-NC 4.0) which permits unrestricted use, distribution, and reproduction in any medium for non-commercial use provided the original author and source are credited.

\section{INTRODUCTION}

Paper currency is widely exchanged for goods and services in countries worldwide. It is used for every type of commerce [1]. At the beginning of the seventies, banknotes and coins were reported as carriers of potentially pathogenic microorganisms [2, 3]. The risk of transmission of pathogenic microorganisms and diseases by currency was reported worldwide but most of these studies were performed in the tropical or subtropical regions of the world [4-6].

Trading has been part of mankind from time immemorial .Items that are passed from hand to hand likely to be contaminated with disease causing microorganisms especially if handled with unclean hand or kept in dirty surrounding [7].
Money is use as a medium for exchange for goods and services, settlement of debts and for deferred payments in economic activities. Daily transactions have made the note to pass through many hands and pathogens become imposed on them before they are finally depositing in banks [8].

The environment plays an important role in transmission of microbial agents to humans, with many environmental materials serving as vehicles, currency notes and coins are one of them. Contamination may occur during production, storage after production and use. Money, therefore presents a particular risk to public health. Currency notes and coins on which pathogenic microorganisms might survive represent an often overlooked reservoir for enteric diseases, food poisoning, wound and skin infections, respiratory and 
gastrointestinal problem to life threatening diseases like septicemia, meningitides etc [9].

The contamination of currency notes could be from several sources; atmosphere during storage, usage, handling or production [10]. The contaminated currency notes go in circulation and contaminate the hands of others, transmitting microorganisms in the process currency and coins are important items most frequently passing from hand to hand during its passing and counting currencies gets contaminated with normal flora and pathogens from the skin, respiratory secretions, gastro-intestinal tract water, soil and aerosols. Most of the people do not care how dirty their hands are when handling and count the money [8].

Currency notes and coins may be act as a universal vehicle for transmission of pathogenic and potentially pathogenic microorganisms among persons directly, either through hand to hand contact, or indirectly, through water and food [11]. The contaminated notes and coins go in circulation and spread-contaminated microbes to others hands and transmitting pathogenic organisms in the process. Potential pathogens have been isolated from currency notes and these include species of Staphylococcus, E. coli and Pseudomonas. Cross contamination by simultaneous handling of money and animal products, poor sanitation practices in market, slaughterhouses and restaurant also increase the risk of infection by multiresistant strains [8].

Survival of various microorganisms on paper money and coins indicates that this could represent a potential cause of sporadic cases of food borne illness and represents an often-overlooked enteric disease reservoir [1]. The presence of pathogenic microorganisms on currency notes is of great concern because the notes might play a role in the transmission and spread of diseases. In the hands of bus conductors and fish and meat sellers, currency notes become literally pestilent. Currency notes carry various bacteria [12].

The objectives is to isolate and identify the pathogenic bacteria from banknotes and coins in Sudan and determine their susceptibility to certain antimicrobial pattern.

\section{MATERIALS AND METHODS Study Design}

A prospective descriptive cross sectional community based study. It was carried out at Khartoum state of Sudan. The study was conducted between the periods of February to May 2016. The currency notes and coins were obtained from different communities namely Bus conductors, Pharmacies at Hospitals, Vegetable sellers and Cafeteria countermen. One hundred samples of coins and currencies (52 coins and 48 currencies) were collected randomly with hands covered with plastic gloves and forceps and were placed immediately into sterile polythene bags and labeled accordingly.

\section{Isolation and Identification of Bacteria}

Sterile cotton swab was dipped in the sterile Peptone water, was rubbed on both the surfaces of currency notes, and then inoculate onto the Blood agar and MacConkey agar (Himedia Company, India) for each note. While coins aseptically transferred into sterile container containing $10 \mathrm{~mL}$ of sterile buffered Peptone water, which was then gently, shaken to give us resultant and incubated overnight at $37^{\circ} \mathrm{c}$ aerobically before inoculation, after overnight incubation the turbidity was observed visually and the subculture made on Blood agar and MacConkey agar (Himedia Company, India). isolation and identification of bacteria by Gram stain and biochemical test (Indole test, Urea hydrolysis test, Motility, Citrate utilization test, Kligler's Iron Agar and Oxidase test for Gram negative bacteria while Catalase test, Coagulate test, Mannitol salt agar medium, DNA-ase test, Litmus milk decolorization, Esculin hydrolysis test, for Gram positive) [13].

\section{Antibiotic Susceptibility Tests}

This test was carried out on Mueller-Hinton agar using the Kirby-Bauer technique (disk diffusion). Using following antibiotics: penicillin $(10 \mu \mathrm{g})$, Gentamicin $(10 \mu \mathrm{g})$, Ciprofloxacin $(30 \mu \mathrm{g})$, vancomycin $(30 \mu \mathrm{g})$, and tetracycline $(30 \mu \mathrm{g})$ (Himedia Company, India). Zone of inhibition measured by millimeters according to CLSI (Clinical Laboratory Standard Institute) [14].

\section{RESULTS}

From the analysis of the 100 paper currency notes (48) and coins (52) were Collected from several area (bus conductors, vegetable sellers, pharmacies, cafeteria countries) in Khartoum city of Sudan, it was established that bacteria and fungi were present on the money.

This study was conducted to isolate pathogenic bacteria from coins and currency in Khartoum city. The result showed that Currency notes were more contaminated with pathogenic bacteria than coins with rate of $55 \%$ to $45 \%$ from total samples. On the other hand, the pathogenic Gram-positive bacteria overwhelm the Gram negative. The most common contaminated money type is coins with $77(46 \%)$ isolate (59 (35\%) one SD and $181 / 2(11 \%) \mathrm{SD})$ while the currencies type showed $96(54 \%)$ isolate (33(19\%) 2SD, 34(20\%) 5SD, 21(14\%) 10 SD and 4(2\%) $20 \mathrm{SD})$.

The total number of all isolates from coins and currency together were 169 , of which the pathogenic organism isolate count $62(36 \%)$ (There were Staphylococcus aureus 28(17\%), followed by Klebsiella pneumoniae 14(8\%), Enterobacter species 9(5\%), 
Enterococcus faecalis 6(4\%), Pseudomonas aeruginosa $3(2 \%)$, Escherichia coli $2(1 \%))$. While the other consider as Normal flora was form 107 (64\%) (There were Bacillus species 33 (20\%), followed by Staphylococcus epidermidis 24(14\%), Micrococcus Species 1(1\%) and fungi was present $49(29 \%)$ of all isolates.

Out of 100, 25 samples were obtained from Bus conductor gave 34 (20\%) organism out of which contributed by Staphylococcus epidermidis, followed by Bacillus species, Staphylococcus aureus and Enterococcus faecalis and fungi of the total bacterial populations on coins and currency.

Out of 100, 40 samples were obtained From Pharmacies yield 83(49\%). Which contributed by Bacillius species 25, followed by Staphylococcus aureus 12, Klebsiella pneumoniae and Staphylococcus epidermidis 8 isolate both shard the same count beside 2 isolate of Pseudomonas aeruginosa and Enterobacter species, and one isolate for each Escherichia coli and Micrococcus Species, 22 fungi isolated from total organisms isolate on coins and currency.

Out of 100, 15 samples were obtained from Cafeteria counters yield $20(12 \%)$ organism, The first position is occupied by Staphylococcus aureus 5,
Bacillius species 3, Staphylococcus epidermidis 2, and in the last position Klebsiella pneumoniae 1 and fungi 9 from the total of isolates.

Out of 100, 20 samples were obtained from vegetables sellers yield 32(19\%) organism, Klebsiella pneumoniae presented the highest count 5 , followed by Enterobacter species 7, Staphylococcus aureus and Staphylococcus epidermidis both shared the same count 4, Enterococcus faecalis 2, Escherichia coli and Pseudomonas aeruginosa count1, fungi 9 from all total isolates.

Antimicrobial sensitivity tests indicated that the pathogenic gram positive isolated was more resistant to majority of use antibacterial when compared with pathogenic gram-negative isolated. Staphylococcus aureus was more resistant to penicillin and more sensitive to ciprofloxacin, while Enterococcus faecalis was more sensitive to vancomycin but resistant to penicillin. Escherichia coli was resistant to vancomycin and sensitive to ciprofloxacin, Klebsiella pneumoniae is more resistant to vancomycin and sensitive to ciprofloxacin, Pseudomonas aeruginosa was resistant to penicillin and sensitive to Gentamycin, Enterobacter species was sensitive to tetracycline and more resistant to vancomycin (Table-1).

Table-1: Showed the Antibiotic Sensitivity Pattern of Microbes isolated from Sudan Currency and Coins

\begin{tabular}{|l|l|l|l|l|l|l|l|l|l|l|l|}
\hline \multirow{2}{*}{$\begin{array}{l}\text { Antibiotics } \\
\text { organisms }\end{array}$} & Penicillin & \multicolumn{2}{l|l}{ Vancomycin } & \multicolumn{2}{l|}{ Ciprofloxacin } & \multicolumn{2}{l|}{ Gentamycin } & \multicolumn{2}{l|}{ Tetracycline } \\
\cline { 2 - 15 } & S & R & S & R & S & R & S & R & S & R \\
\hline Staphylococcus aureus & 6 & 21 & 23 & 4 & 27 & 0 & 27 & 0 & 23 & 4 \\
\hline Staphylococcus epidermidis & 15 & 5 & 17 & 3 & 20 & 0 & 20 & 0 & 15 & 5 \\
\hline Enterococcus faecalis & 0 & 3 & 3 & 0 & 3 & 0 & 3 & 0 & 3 & 0 \\
\hline Escherichia coli & 0 & 2 & 0 & 2 & 2 & 0 & 2 & 0 & 2 & 0 \\
\hline Klebsiella pneumoniae & 0 & 9 & 1 & 8 & 9 & 0 & 9 & 0 & 9 & 0 \\
\hline Pseudomonas aeruginosa & 0 & 3 & 0 & 3 & 3 & 0 & 3 & 0 & 3 & 0 \\
\hline Enterobacter species & 2 & 9 & 4 & 7 & 11 & 0 & 10 & 1 & 11 & 0 \\
\hline Micrococcus Species & 0 & 1 & 0 & 1 & 1 & 0 & 1 & 0 & 1 & 0 \\
\hline
\end{tabular}

\section{DISCUSSION}

The results of this study revealed that currency notes and coins were commonly contaminated with various bacteria. We found that $97 \%$ of tested currency notes and coins were contaminated with bacteria, which our study disagree with previously reported studies from Tanzania [15], India [16, 17], and where almost all the notes were contaminated Different species of bacteria isolated in our study are almost agree with the studies done in Nepal [18], Iraq [8] and Nigeria [7]. All these studies established gram-positive bacteria as the major isolates from the contaminated coins and currencies.

Transmission of microorganisms is possible from any place where they are attached. Hand to hand Transfer of money plays important role in spread of diseases The number of transferring organisms from coins or notes depends on a series of factors such as
The number of organisms present and their ability to survive in dry environment [19]. The form of contact also makes a difference, whether it is by touching contaminated money, which can transfer the organisms to the hand The source of contamination may be chiefly dirty hands, food and water. Coliform and Staphylococcus aureus can be re-introduced in food by many ways. It was observed that, during vending operations, the same hand alternatively served and held food and money [20].

Money handling constitutes another risk factor of street food contamination [12]. These routes of transmission are of great importance in the health of many populations in developing countries where the frequency of infection is general indication of local hygiene and environmental sanitation levels. To date no outbreaks of foodborne and other illness have been associated with infection from money. However, 
evidence for the presence of pathogenic bacteria on currency reinforces the need for strict adherence to hygienic practices among money handlers who also handle food and water.

This study show higher frequencies of Staphylococcus aureus and klebsiella pneumoniae similar to the results obtained by $[21,16]$. They had collected currency notes and coins from different communities e.g. Bus conductors, public toilets agents and pharmacies to reveal the bacteria profile of circulating coins and currency notes [21], other study tested to isolate various loads of microorganisms on currency notes and coins [16]. At the same time lower frequencies was appeared with Escherichia coli, Citrobacter species and Pseudomonas aeruginosa in both studies.

This study also showed lower frequencies in Staphylococcus aureus, Klebsiella pneumoniae and Escherichia coli than the studies that made by [15] in Tanzania and [8] in Iraq. Also show higher frequencies in staphylococcus than the previous study that made by [18]. In other hand in this study absence or little resistance against Gentamycin and Ciprofloxacin was appeared with same study that done by [8].

In addition, this study showed higher frequencies in Staphylococcus aureus than the other studies that was done by $[22,17]$. At the same time lower frequencies with Escherichia coli was appeared in both studies.

It can be concluded that currencies and coins in (bus conductors, pharmacies, cafeteria counters and vegetables seller) is commonly contaminated with different pathogenic and potential pathogenic bacteria and all the people handling currency are invariably exposed to those microorganisms. So, awareness related to the improvement of personal hygiene and good money handling practice such as washing hands properly with soap and water after handling currency before eating and avoiding using saliva during counting money are strongly recommended as the main pillar to reduce the risk of infection. It is suggested that the public should be further enlightened on the importance of hand wash act at restaurants and homes and after going to the toilet and we expect that regular usage of disinfectants during COVID-19 pandemic will reduce contamination of moneys with pathogens.

\section{REFERENCES}

1. Barry, M. (2002). Handling money and serving ready to eat food. Food Service Technology 2: 13. Georgia-Pacific Corporation, 190 County Road 216, Palatka, USA. FL 32178-0919.

2. Jiang, X., \& Doyle, M. P. (1999). Fate of Escherichia coli O157:H7 and Salmonella enteritis's on currency. J Food Prot. 62: 805-807.
3. Khin, N. O., Phyu, P. W., Aung, M. H., \& Aye, T. (1989). Contamination of currency notes with enteric bacterial pathogens. J Diarrhoeal Dis Res India. 7: 92-94.

4. Ahmed, S. U., Parveen, S., Nasreen, T., \& Feroza, B. (2010). Evaluation of the microbial contamination of Bangladesh paper currency notes (Taka) in circulation. Adv Biol Res. 4: 266-271.

5. Enemuor, S. C., Victor, P. I., \& Oguntibeju, O. O. (2012). Microbial contamination of currency counting machines and counting room environment in selected commercial banks. Nigeria Sci Res Essays. 17:1501-1511.

6. Yazah, A., Yusuf, J., \& Agbo, A. J. (2012). Bacterial contaminants of Nigerian currency notes and associated risk factors. Research journal of Medical sciences, 6(1), 1-6.

7. Umeh, E. U., Juluku, J. U., \& Ichor, T. (2007). Microbial contamination of Naira (Nigerian currency) notes in circulation. Res J Environ Sci. 1: 336-339.

8. Siham, J., Halima, M., \& Zari, S. (2015). Bacterial contaminations of Iraqi Currencies collected from Duhok city, Iraq. Res Med Sci, 3(7): 1712-1716.

9. Elumalai, E. K., David, E., \& Hemachndran, J. (2012). Bacterial contamination of Indian currency notes (rupee). Indian Journal of Occupational and Environmental Medicine. 3, 204-205.

10. Awodi, N. O., Nock, I. H., \& Aken'Ova, I. (2001). Prevalence and public health significance of parasitic cysts and eggs on the Nigerian currency. Niger J Parasitol. 22: 137-142.

11. Xu, J., Moore, J. E., \& Millar, B. C. (2005). Ribosomal DNA (rDNA) identification of the culturable bacterial flora on monetary coinage from 17 currencies. J Environ Health. 67:1-7.

12. Barro, N., Bello, A., Savadogo, C. A. T., Ouattara, A., Ilboudo, J., \& Traore, A. S. (2006). Hygienic status assessment of dish washing waters, utensils, hands and pieces of money from street food processing sites in Ouagadougou (Burkina Faso), African Journal of Biotechnology. 5(11): $1107-$ 1112.

13. Cheesbrough, M. (2006). District Laboratory Practice in Tropical Countries, part 2. Second Edition, Cambridge, Cambridge University Press.

14. Hudzicki, J. (2013). Kirby-Bauer Disk Diffusion Susceptibility Test Protocol [serial online]. ; http://www.microbelibrary.org/component/resourc e/laboratory-test/3189-kirby-bauer-disk-diffusionsusceptibility-test-protocol.

15. Neel, R. (2012). Bacteriological examination of paper currency notes in Tanga in Tanzania. International Journal of Pharmaceutical Sciences Review and Research, 16, 9-12.

16. Mukhopadhyay, M., Podder, S., \& Bhattacharya, S. (2015). Microbial Contamination of Indian Currency Notes and Coins in Kolkata, West Bengal-A Survey. Biomedical Science, 4(8). 
17. Khan, M. R., Venkatesh, R. K., Ravi, N., Ravikumar, R., \& Kumar, S (2013). Assessment of microbial contamination of Indian paper currency notes in circulation. International Journal of Recent Scientific Research. 4, 1516-1518.

18. Prasai T., Yami, K. D., \& Joshi, D. R. (2008). Microbial load on paper/ polymer currency and coins. Nepal J Sci Technol. 9:105-109.

19. Beumer, R. (2007). Filthy lucre New Scientist Magazine USA. No. 2634: 81.

20. Barro, R. J. (2002). Quantity and quality of economic growth. Banco Central de Chile.
21. Thiruvengadam, S., Shreenidhi, K. S., Vidhyalakshmi, H., Ramya, M., Kamala, T., Sundararaman, T. R., \& Selvi, R. (2014). A study of bacterial profiling on coins and currencies under circulation and identifying the virulence gene in Chennai (TN). International Journal of ChemTech Research, 6(9), 4108-4114.

22. Pal, K., Das, N. S., \& Bhattacharya, S. (2013). Bacteriological profile of Indian currency circulating in a tertiary care hospital in rural Bengal. Indian Journal of Research and Reports in Medical Sciences. 3, 23-27. 